DOI: $10.17516 / 1997-1370-0708$

УДК 376.3:[378.016:796.01]

\title{
The Personification of Students with Health Issues in the Process of Physical and Recreation Activities
}

\author{
Olesya A. Golubeva, Vladislav V. Alontsev, \\ Olga A. Alontseva and Olga V. Sprikut* \\ Nosov Magnitogorsk State Technical University \\ Magnitogorsk, Russian Federation
}

Received 18.11.2020, received in revised form 15.12.2020, accepted 22.01.2021

\begin{abstract}
The problem of training students with health issues is the most relevant today. Education at the university should be carried out in conditions that allow students to adapt and fulfill their educational needs. In this regard, one of the promising directions for improving the performance of students with various health issues is the organization of physical and health-improving activities. Systematic sport activities stimulate positive reactions in the system and functions of the body, forming necessary motor coordination, physical qualities and abilities aimed at life support, development and improvement of a disabled person's body. The personalized approach to planning and organizing classes with such students contributes to the belief that physical education is an objective living need for them, a way and condition for living a full life. In the process of training, the future specialist gets the necessary knowledge and skills for health preservation, which in future allows them to have a career in the professional sphere, stimulates self-understanding and self-prediction of their activities.
\end{abstract}

Keywords: students with health issues, personification, physical and health activities.

Research area: physical education.

Citation: Golubeva, O.A., Alontsev, V.V., Alontseva, O.A., Sprikut, O.V. (2021). The personification of students with health issues in the process of physical and recreation activities. J. Sib. Fed. Univ. Humanit. Soc. Sci., 14(2), 166-172. DOI: 10.17516/1997-1370-0708.

(c) Siberian Federal University. All rights reserved

* Corresponding author E-mail address: o.golubeva@magtu.ru,kaffv@mail.ru ORCID: 0000-0001-7108-4772 (Golubeva); 0000-0002-7509-2371 (Alontsev) 


\title{
Персонификация личности студента с отклонениями в состоянии здоровья в процессе физкультурно-оздоровительной деятельности
}

\author{
О.А. Голубева, В.В.Алонцев, \\ О.А.Алонцева, О.В. Сприкут \\ Магнитогорский государственный технический университет \\ Российская Федерачия, Магнитогорск
}

\begin{abstract}
Аннотация. Проблема профессиональной подготовки обучающихся с отклонениями в состоянии здоровья сегодня наиболее актуальна. Образование в вузе должно осуществляться в условиях, которые позволяют личности адаптироваться и реализовывать образовательные потребности. В связи с этим одним из перспективных направлений повышения работоспособности студентов с ограниченными возможностями здоровья является организация физкультурно-оздоровительной деятельности. Занятия физической культурой стимулируют позитивные реакции в системах и функциях организма, формируя тем самым необходимые двигательные координации, физические качества и способности, направленные на жизнеобеспечение, развитие и совершенствование организма инвалида. Персонифицированный подход к планированию и организации занятий с таким студентом формирует убеждение в том, что физическая культура является для него объективной жизненной потребностью, способом и условием полноценной, полноправной жизни. Будущий специалист в процессе занятий осваивает необходимые знания и умения по здоровьесбережению, здоровьесохранению, что в дальнейшем позволяет ему реализоваться в профессиональной сфере, стимулирует к самопониманию, самопрогнозированию себя и своей деятельности.
\end{abstract}

Ключевые слова: студенты с ограниченными возможностями, персонификация, физкультурно-оздоровительная деятельность.

Научная специальность: 13.00.04 - теория и методика физического воспитания.

Постановка проблемы. В последнее время российские вузы сталкиваются с проблемой значительного повышения количества студентов, имеющих отклонения в состоянии здоровья. На уровень здоровья молодежи оказывают негативное влияние наследственные факторы, политические, экономические, культурные изменения в обществе, а также интенсивный ритм жизни, психологическая напряженность и дискомфорт, хроническая усталость, вредные привычки, некачественное питание, гиподинамия, неблагоприятная экологическая обстановка. Кроме того, период обучения сопровождается малоподвижным образом жизни, повышенным уровнем учебной на- грузки, что вызывает нарушения в работе систем организма, его функциональном состоянии. Пролонгированные во времени мышечные напряжения, которые не снимаются движениями (действиями), являются стрессом (Bazarnyy, 2004), что вызывает рост психических расстройств среди студентов, снижает их работоспособность.

В период профессиональной подготовки молодежи в вузе вопрос сохранения и укрепления здоровья стоит не менее остро, чем в школьные годы, поскольку только полноценно развитая личность способна полностью реализоваться как специалист, успешно адаптироваться к социальным условиям, к профессиональной деятельности. 
Обсуждение. Сегодня результатом профессиональной подготовки в высших учебных заведениях является сформированность компетенций, характеризующихся не только объемом и качеством полученных знаний, умений и навыков, но и личностными и профессиональными качествами. В федеральных государственных образовательных стандартах высшего образования предусмотрены дисциплины, освоение которых направлено на формирование способности у будущего специалиста поддерживать должный уровень физической подготовленности для обеспечения полноценной социальной и профессиональной деятельности.

Наибольшие возможности для этого имеет оздоровительная физическая культура. Физкультурно-оздоровительная деятельность играет огромную роль в формировании условий обучения, труда и жизнедеятельности. Она направлена на сохранение и укрепление здоровья, повышение работоспособности обучающихся, позволяет достичь физического, духовного и культурного совершенства, повышает двигательную, трудовую и творческую активность, является совершенным фактором формирования образа жизни каждого человека в отдельности и всего общества в целом.

Физкультурно-оздоровительная деятельность реализует принцип оздоровительной направленности, являясь средством активного полноценного отдыха людей, инструментом профилактики асоциального поведения молодежи, способствует снижению социальной напряженности в обществе, создает условия для социальной адаптации людей, что особенно важно для лиц с отклонениями и ограниченными возможностями здоровья.

Молодые люди с отклонениями в состоянии здоровья физиологически незрелы, у них отмечается мышечная гипотония (тонкие и слабые мышечные волокна, низкий мышечный тонус), который сопровождается снижением двигательной активности. Они отличаются слабым типом нервной системы, малой выраженностью положительных эмоций, сниженным иммунитетом, низкой умственной и физической работоспособностью (Golikova, 2015b).
Основное заболевание, сопутствующее или вторичные изменения в организме неизбежно трансформируют личность студента с отклонениями в состоянии здоровья. Инвалидность вносит свою специфику в структуру личности, формируя мотивы, связанные с социальной адаптацией. Наличие внешнего дефекта усиливает проблему общения, межличностных отношений, самооценка человека занижена или противоречива. В ходе педагогического взаимодействия преподавателя и студента с ограниченными возможностями здоровья необходимо создавать такие условия, которые обеспечат гармоничность развития внутреннего мира обучающегося, содействие самопониманию и самопринятию им собственной сущности (Golikova, 2015a).

Современное профессиональное обучение студентов с отклонениями в состоянии здоровья должно быть персонифицированным. Персонификация личности в исследованиях Б. Д. Парыгина представлена как целый комплекс тенденций изменения и развития личности, который включает в себя процесс духовного обогащения, рост самосознания и духовного потенциала человека, личностную активность (Zhuravlev, Nikitina, Kharlamenkova, 2019).

Сущность процесса персонификации как способа педагогической деятельности состоит в осознанной саморегуляции поведения обучающегося в образовательных процессах, постоянно стимулируемой (с помощью различных технологий) педагогами. Только на этой основе возможен постепенный переход к самообучению и последующему самообразованию (Yesaulovoy, 2010: 18).

Персонификация личности будущего специалиста позволит содействовать становлению ряда профессиональных качеств и компетенций с учетом специальности. Она становится основой целостности личности будущего специалиста, самоактуализации, саморазвития, осознания желаний, предпочтений и субъективных реакций, формирования собственной объективной картины мира. Подход с позиции персонифицированного образования позволяет студенту с ограниченными возможностями здоровья по-новому осмыслить важнейшие сферы 
и формы современной социокультурной жизни, а главное, осознать свои позиции, смыслы и цели, реализуемые в процессе образования и обращенные в будущее, отрефлексировать образование, которое он получает, с учетом качества жизни, с учетом основного заболевания, вторичной патологии и сопутствующих заболеваний, ценностей современной жизни и культуры и тем самым обогатить свою исходную мотивацию, связанную с его приобретением.

Это и явилось важным стимулирующим фактором для применения стратегий персонификации обучения студентов с ограниченными возможностями здоровья, так как стили здорового образа жизни для студентов данной категории становятся приоритетной мотивационной основой развития потребностей в самопознании и саморегуляции на его основе процессов самообучения (Golikova, 2015b).

Назрела необходимость пересмотра прежних концепций физического воспитания, его организации. В.К. Бальсевич, Е. П. Ильин, Л.И. Лубышева, А. В. Чоговадзе, М. М. Рыжак (Balsevich, 1995; Ilin, 1994; Lubysheva, 1990; Lubysheva, 1992; Chogovadze, 1993) отмечают, что система физического воспитания должна быть перестроена таким образом, чтобы студент из объекта социально-педагогического воздействия стал субъектом активной творческой деятельности на основе развития внутренних мотивов к самосовершенствованию и самоопределению, чтобы наблюдалась демократизация в отношениях участников педагогического процесса, формировалась у молодежи мотивация разностороннего и гармонического развития и т. д.

Современным подходом в организации физического воспитания является полный учет индивидуальных морфофункциональных и психологических особенностей человека, соответствие физических нагрузок этапу возрастного развития человека. Предусматривается также свобода выбора форм и интенсивности занятий, содействующих физическому совершенствованию и укреплению здоровья (Golikova, 2015b).

Персонификация в физкультурнооздоровительной деятельности обучающихся заключается в использовании индивидуального, дифференцированного подхода к подбору упражнений для студентов с различными заболеваниями с учетом их возможностей и пожеланий, в контроле за правильностью выполнения упражнений и сопровождении, ориентирующем на самостоятельность, саморазвитие, умение проектировать свою деятельность.

Обучающиеся, имеющие отклонения в состоянии здоровья, могут заниматься в специальной медицинской группе, а также со студентами основной группы здоровья в рамках инклюзивного образования, но при этом необходимо оценить уровень их физической подготовленности, работоспособности и адаптации к физическим нагрузкам (Ovsyannikova, 2019).

Персонифицированные физкультурнооздоровительные занятия позволяют студентам с отклонениями в состоянии здоровья овладеть системой знаний и умений по физической культуре, здоровьесохранению, здоровьесбережению, формируя свои способности.

Занятия физическими упражнениями для обучающихся - инвалидов по зрению жизненно необходимы, так как они являются одновременно средством физической, медицинской и социальной реабилитации. Они повышают приспособляемость таких обучающихся к жизненным условиям, расширяют их функциональные возможности, способствуют оздоровлению организма, формируют гигиенические навыки. Особенно важно то, что занятия физическими упражнениями благоприятно влияют на психику инвалидов по зрению, мобилизируют их волю, побуждают к сознательному участию в жизни коллектива, возвращают чувство социальной полноценности, способствуют установлению социальных контактов.

В рамках инклюзивного образования занятия по физической культуре для таких студентов проводят вместе с обучающимися основной группы здоровья, которые в качестве гайдов помогают при выполнении беговых упражнений, при перемещении по залу, являются партнерами в парах. Физкультурно-оздоровительные занятия для слепых и слабовидящих студентов 
включают специальный комплекс общеразвивающих упражнений с предметами и без них (гантели, гимнастические палки, мячи, фитболы, фитнес-резинка), которые выполняются под музыкальное сопровождение.

Также на занятиях используются гимнастические скамейки, гимнастические стенки, велотренажеры, степы и батут для развития координационных способностей, умения ориентироваться в пространстве.

Физические упражнения способствуют развитию у занимающихся гибкости и подвижности суставов, силы, выносливости, координации движений, а также содействуют общему укреплению организма, формированию правильной осанки.

При планировании физкультурнооздоровительных занятий с глухими студентами используются упражнения, направленные на развитие всех основных физических качеств. Как правило, у глухих студентов наблюдаются нарушения равновесия, точности движений, пространственной ориентировки, нарушение скоростных и обратных реакций, работы вестибулярного аппарата. При проведении занятий с такими студентами применяют общеразвивающие упражнения с предметами и без них (гантели, гимнастические палки, мячи, фитболы, фитнес-резинка), упражнения в парах, игровые ситуации, а также элементы йоги и самомассажа. Наряду с методом строго регламентированного упражнения наглядный является одним из основных, при реализации которого осуществляется показ движений со словесным сопровождением преподавателя, уточняющей мимикой, жестами, речью для считывания с лица и одновременным выполнением упражнений по подражанию и сопряженной речью.

При изучении и освоении базовых движений студенты получают задания по самостоятельному составлению комплексов упражнений для выполнения в домашних условиях, используя для этого материал образовательного портала и знания, полученные на практических занятиях.

Для закрепления освоенных движений для студентов с ограниченными возмож- ностями организуются игровые ситуации и соревнования, например «Веселые старты».

Использование на занятиях разнообразных средств, направленных на воспитание основных физических качеств, упражнений циклического и ациклического характера, а также элементов тяжелой атлетики, атлетической гимнастики, спортивных и подвижных игр позволяет разнообразить физкультурные занятия, учесть индивидуальные возможности и способности каждого занимающегося, дозировать нагрузку, повысить интерес и мотивацию к систематическим занятиям физической культурой, тем самым создать возможность для каждого студента с ограниченными возможностями здоровья физически развиваться и совершенствоваться, приобрести психологическую уверенность в собственных силах.

Примером тому явилась работа с инвалидом с детства, у которого от рождения отсутствовала рука до локтевого сустава. В связи с неравномерным распределением нагрузки на одну конечность наблюдалась атрофия плеча и спины со стороны культи. С другой стороны тела, наоборот, очень сильный гипертонус мышц и, как следствие, нарушение осанки, отклонения в положении лопаток и пр. В психологическом плане у студента был занижен уровень самооценки, лабильная психика.

Разработанные специально для такого студента комплексы, включающие упражнения с отягощением (грузовую манжету) для культи, с фитнес-резинкой и с сопротивлением для развития силы мышц и повышения мышечной массы со стороны атрофированных участков, а также упражнения для снижения гипертонуса и для расслабления с использованием массажа и фитбола позволили добиться видимых изменений уже через три месяца регулярных занятий. А через полгода восстановилось положение лопаток, выровнялась осанка, плечи в объеме стали одинаковыми. Также был составлен и освоен комплекс упражнений для самостоятельных занятий в домашних условиях. У студента сформировалось желание и интерес к занятиям физической культурой и спортом, повысилась самоо- 
ценка, появилась уверенность в себе, вернулось чувство социальной защищенности и полезности.

Индивидуально подобранные упражнения и составленные комплексы из них с учетом отклонений в состоянии здоровья занимающихся направлены на поддержание ремиссии болезни, восстановление двигательной активности и улучшение функционального состояния организма каждого.

Для того чтобы дети и молодежь с отклонениями в состоянии здоровья могли целенаправленно работать над собой, необходимо, чтобы субъект осознавал здоровье как высшую человеческую ценность и обладал необходимым запасом знаний для осуществления такой работы. Персонификация личности в процессе физкультурнооздоровительной деятельности способствует формированию мотивации на здоровый образ жизни, стремлению сохранять и укреплять свое здоровье самостоятельно (Golikova, 2015b).

Индивидуальная направленность программы физического воспитания для обучающихся с отклонениями в состоянии здоровья позволит повысить плотность двигательной активности, тем самым улучшая функциональные возможности систем организма, способствуя укреплению организма в целом, благоприятно воздействуя на психическое и эмоциональное состояние человека.

Привлекать студентов с отклонениями в состоянии здоровья к систематическим занятиям физической культурой просто необходимо, применяя в работе с ними индивидуальный дифференцированный, персонифицированный подход. Не следует предлагать им альтернативу в виде освобождения от практических занятий по состоянию здоровья, написания реферата или сообщения для получения зачета, а нужно позволить обучающимся познать собственный потенциал, осознать потребность в двигательной активности, стать полноценной личностью, скорректировать дефекты сопутствующих заболеваний и вторичных отклонений, выработать компенсаторные механизмы осуществления жизнедеятельности, укрепить свое здоровье.
Заключение. В процессе физкультурнооздоровительной деятельности формируется комплекс специальных знаний, жизненно и профессионально необходимых сенсорноперцептивных и двигательных умений и навыков; развиваются основные физические и психические качества; повышаются функциональные возможности различных органов и систем; развиваются, сохраняются и используются в новом качестве оставшиеся в наличии телесно-двигательные характеристики. Обеспечивается общая и профессионально-прикладная физическая подготовленность, определяющая психофизическую готовность студента к будущей профессии. Приобретается опыт творческого использования физкультурно-спортивной деятельности для достижения жизненных и профессиональных целей.

Кроме того, в процессе персонифицированной физкультурно-оздоровительной деятельности возможно формирование у человека с ограниченными возможностями здоровья устойчивой мотивации и потребности в занятиях доступным видом спорта, что может стать способом самореализации, творческого саморазвития, самовыражения, независимости и уверенности в себе. Это открывает возможности позитивного изменения биологического и социального статуса (Golikova, 2015b).

Таким образом, персонификация личности в физкультурно-оздоровительной деятельности обучающихся с отклонениями в состоянии здоровья должна стать основной тенденцией современного профессионального образования. В процессе обучения в вузе такие студенты должны не только сформировать профессиональные компетенции, освоить азы будущей профессии, но и научиться самостоятельно планировать и организовывать свою деятельность, направленную на формирование и сбережение собственного здоровья. В процессе физкультурнооздоровительных занятий студент с отклонениями в состоянии здоровья познает себя, получает необходимые знания о своем организме, определяет и осваивает, проявляя творчество, те средства, которые эффективно воздействуют на его функциональные, физи- 
ческие возможности, создают благоприятный эмоциональный фон и в дальнейшем позволят ему вести полноценную жизнь, реализоваться в профессиональной деятельности.

\section{Список литературы / References}

Bazarnyy, V.F. (2004). Shkolnyy stress i demograficheskaya katastrofa Rossii [School stress and demographic catastrophe in Russia]. Moscow, Sergiyev Posad, 96 p. Available at: http://www.hrono.ru/libris/ lib_b/bazar04.html

Balsevich, V.K (1995). Fizicheskaya kultura: molodezhi sovremennost [Physical culture: youth and modernity]. In Teoriya i praktika fizicheskoy kultury [Theory and Practice of Physical Culture], 5, 7-8.

Chogovadze, A.V. (1993) Fizicheskoye vospitaniye i formirovaniye zdorovogo obraza zhizni studentov [Physical education and healthy lifestyle of students], In Teoriya i praktika fizicheskoy kultury [Theory and Practice of Physical Culture], 7, 8-10.

Golikova, Ye.M. (2015a). Tekhnologii formirovaniya individualnykh obrazovatelnykh trayektoriy studentov s ogranichennymi vozmozhnostyami zdorovya [The technologies for forming individual educational trajectories of students with disabilities]. In Sovremennyye tendentsii razvitiya nauki i tekhnologiy: sbornik nauchnykh trudov po materialam II Mezhdunarodnoy nauchno-prakticheskoy konferentsii 31 maya 2015 g.: $v 7 \mathrm{ch}$. [Modern trends in science and technologies: Proceedings of the II International Scientific and Practical Conference]. Belgorod, 143-149.

Golikova, Ye.M. (2015b). Obrazovaniye studentov s ogranichennymi vozmozhnostyami zdorovya na osnove individualnykh obrazovatelnykh trayektoriy [The education of students with disabilities based on individual educational trajectories]. Chelyabinsk, Tsitsero, $147 \mathrm{p}$.

Ilin, Ye.P. (1994). Ot kultury fizicheskoy - k kulture zdorovya [From physical culture to health culture]. In Teoriya i praktika fizicheskoy kultury [Theory and Practice of Physical Culture], 7, 46-48.

Lubysheva, L.I. (1990). O programmnykh osnovakh vuzovskogo fizkulturnogo vospitaniya [About the programme frameworks of university physical education]. In Teoriya i praktika fizicheskoy kultury [Theory and Practice of Physical Culture], 3, 42-44.

Lubysheva, L.I. (1992). Kontseptsii formirovaniya fizicheskoy kultury cheloveka [The concepts of human physical culture formation]. Moscow, GTSOLIFK. $120 \mathrm{p}$.

Ovsyannikova, T.G. (2019). Problemy prepodavaniya fizicheskoy kultury studentam s oslablennym zdorovyem [The problems of teaching physical culture to students in poor health]. In Aktualnyye problemy sovremennoy nauki, tekhniki i obrazovaniya: tezisy dokladov 77-y mezhdunarodnoy nauchno- tekhnicheskoy konferentsii [Important Problems of Today's Science, Engineering and Education 77 International Conference]. Magnitogorsk. 2. 414. Available at: http://apmste.magtu.ru/images/doc/2_2019.pdf

Yesaulovoy, M.B. (2010). Personifikatsiya vysshego professionalno-pedagogicheskogo obrazovaniya: na puti k samoupravlyayemoти obucheniyu: monografiya [The personalization of higher vocational-pedagogical education: on the way to self-governing training]. SPb, SPGUTD, $160 \mathrm{p}$. Available at: http://ext.spb. ru/2011-03-15-04-30-15/category/6-pedagogika.html?download=38\%3Apersonifikatsiya-vysshego-professionalno-pedagogicheskogo-obrazovaniya-na-puti-k-samoupravlyaemomu-obucheniyu

Zhuravlev, A.L., Nikitina, Ye.A., Kharlamenkova, N.Ye. (2019). Metodologiya, teoriya, istoriya psikhologiya razvitiya lichnosti [The methodology, theory, history and psychology of personality development]. Moscow, Institut psikhologii RAN, 734 p. Available at: https://pure.spbu.ru/ws/portalfiles/portal/49384234/_1.pdf 